\title{
Design and Implementation of Smart and Low Cost Multi-task Farming System Using Arduino
}

\author{
Uppu Shasi Kiran ${ }^{1 *}$, Shanu Arya ${ }^{2}$, M. Rajasekaran ${ }^{3}$ \\ Department of Computer Science and Engineering, \\ SRM Institute of Science and Technology, KTR Campus Chennai, Tamil Nadu, India, 603203. \\ * Corresponding Author E-mail: u.shasi.shasi143@gmail.com
}

\begin{abstract}
Using the idea of IOT this project explain the multi-task farming system using Arduino. The system uses a Wi-Fi module in which system is connected to the internet. A motor and two valve are controlled by this module for transporting the water to the farm on receiving the signal from a water level sensor and soil moisture indicator. This system explain the illustration of Internet of Things (IOT). This concept does the work like weeding, spraying water, harvesting, etc. The system also does the work like determining the humidity of the soil and measuring the physical environmental factor which can be monitored by any individual from anywhere they want and the data gets recorded in the database of the webpage or the app through IOT connection and the individual gets a notification on their cellular phone through message so that he can operate the system through a push message or can be done through the mobile app if there is any requirement to the field that to be taken care of.
\end{abstract}

Keywords: Arduino, IOT, Sensors, GSM, Wi-Fi, Automation.

\section{Introduction}

Agriculture is the main sector of Indian economy. In India, monsoon plays an important role in fulfilling the water needs which is required for farming throughout the year which is insufficient source for irrigation. In irrigation system, two things are required, first thing is that to know the idea of soil fertility and other thing is to measure the moisture variability in soil. Thesedays, for farming, specific techniques are implemented to reduce the reliance of monsoons. This technique is controlled by electrical power or we can place solar panels to the prototype. In this project, water level sensors are placed in the water tank and soil moisture sensors are placed at the root level of the plant and there are many other sensors are placed in the soil to know the readings of the soil.

In India literature rate is gradually increasing and as we know now-a-days none of the farmer family's young ones are willing to take their culture of cultivating so day by day farmer numbers are going and many are killing themselves because of their poverty so here we are, where we need automation in cultivating sector which would take off the burden on the people who would like to do a job as well as have a control over their fields without being actually present but able to see what is going on with their cultivation.

So it's now time to take the cultivation process to next level in the human history, now works on artificial intelligence is also growing rapidly so in coming years the world would experience most of the robotic work so if we take the cultivation and if we combine it with AI, would literally be a revolutionary work. In this journal, a new ensemble technique is presented for effective cultivation process, we will be using a prototype which would be set for the field and it would do a lot of work on field without any human power requirement but requires some monitoring because we are not using any artificial intelligence which would help prototype to work on itself.

\section{Literature Survey}

There are many works have been proposed by various researchers in the past. Among them, Genghuang Yang Boying Wen used technology of Automated Irrigation System in which he used GSM network and radio communication Technologies based on programmed microcontroller and implemented the concept of GSM (global system mobile) network and radio communication. Request and order can be managed from the Personal Computer platform or cellular phone to the microcontroller and the information such as, soil moisture, temperature and soil humidity level sampled by the microcontroller can also be sent to the Personal Computer platform or cellular phone by GSM push message which provided with the advantage of Can be accessed from any location through GSM No manual labour required Remote Monitoring Remote Control

Joaquín Gutiérrez Juan Francisco, Alejandra Nieto Garibay Miguel, Ángel Porta-Gándara proposed and used technology of Wireless Sensor Unit and Wireless Input Unit, based on microcontroller, Raspberry pi, and GSM technology and the concept which explained an automatic farming system which was developed to control water use for farming crops. The system proposed the use of wireless sensors network of soil-moisture and temperature sensors placed in the root level of the plants.

Ankita Patil, Mayur Beldar, Akshay Naik, proposed this system works on the data mining techniques \& data obtained from satellite information, Internet, from soil testing report fed in the existing databases and the concept which they derived is Arduino based automatic plant watering system and android application which will help to control Arduino via internet. Also, this android 
application provides farmers with agricultural related information such as costs of seeds, moisture level required, type of soil needed, weather forecast, fertilizers and pesticides to be used.

\section{Proposed Work}

In this paper, a new ensemble approach is proposed of introducing a prototype in agriculture fields for automating the cultivation process, this project involves use of microcontroller (Arduino), Sensors, IOT (through which we can get the data, which will be recorded in the database), WIFI or GSM (for getting the push messages to cellular phone about the conditions of the field), we can divide this project into 2 phases, In phase one we can see the embedded part which will be installed in the field and does the work which a human capable of doing the work but as we are automating the cultivating system so we are using a prototype which would does the work with some simple instructions which can handled by the following recipient .

The field which would be placed as the picture shown below

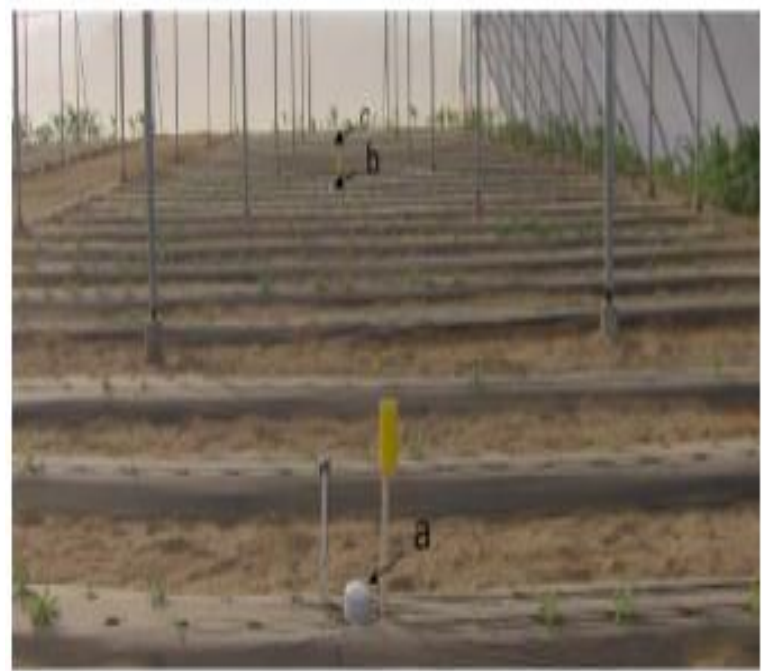

The sensors will be placed in this field and the readings of the soil will be sent to the microcontroller and through which we get the data recorded in to the database through IOT and we would receive a push message notification into the following recipient's cellular phone so that he would get knowledge what is the condition of the field and can send the instructions to the prototype so that it would follow the instructions as per the instruction been coded down to be followed.

\section{Phase 1:}

The phase one if we look at there will be sensors and microcontroller, as the picture shown below.

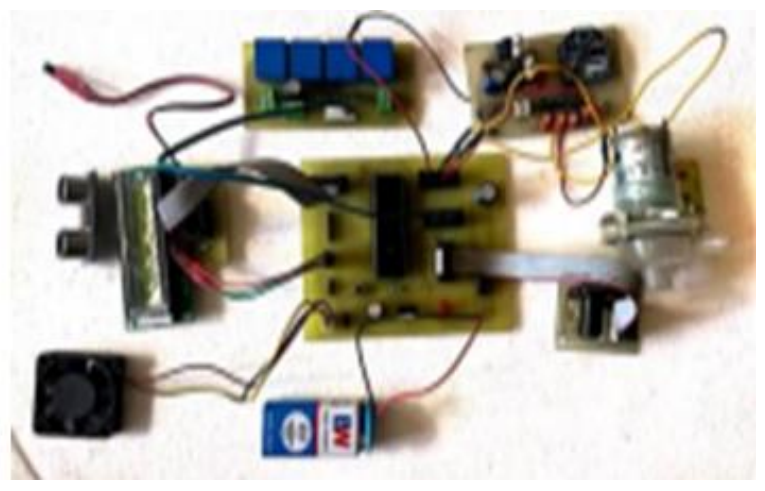

Phase 2:

In this we will connect the prototype to IOT and the readings would be recorded in the database of the webpage which would be developed for controlling the prototype and recorded data will be sent by the microcontroller.

\section{Result and Discussion}

The experimenting system for the prototype consists of a moveable robot with cellular server, wifi module, camera if needed in front of the robot and many other sensors. All the sensors are very successfully embedded with a microcontroller and the microcontroller is connected with Arduino. Wi-Fi and camera in front are also connected to Arduino. Testing results show that the prototype can be controlled from anywhere using wireless connection through PC commands or through push message through GSM connection to cellular phone sends the orders \& requests to microcontroller and microcontroller gives signals to motor placed on the robot in order to perform it's task.

- $\quad$ The performance can be recorded as the sample picture shown below. There the data recording analysis can be analysed by providing the 'from' date and 'to' date. Web application for the automated irrigation system to remotely supervise the soil moisture and temperature of each WSU.

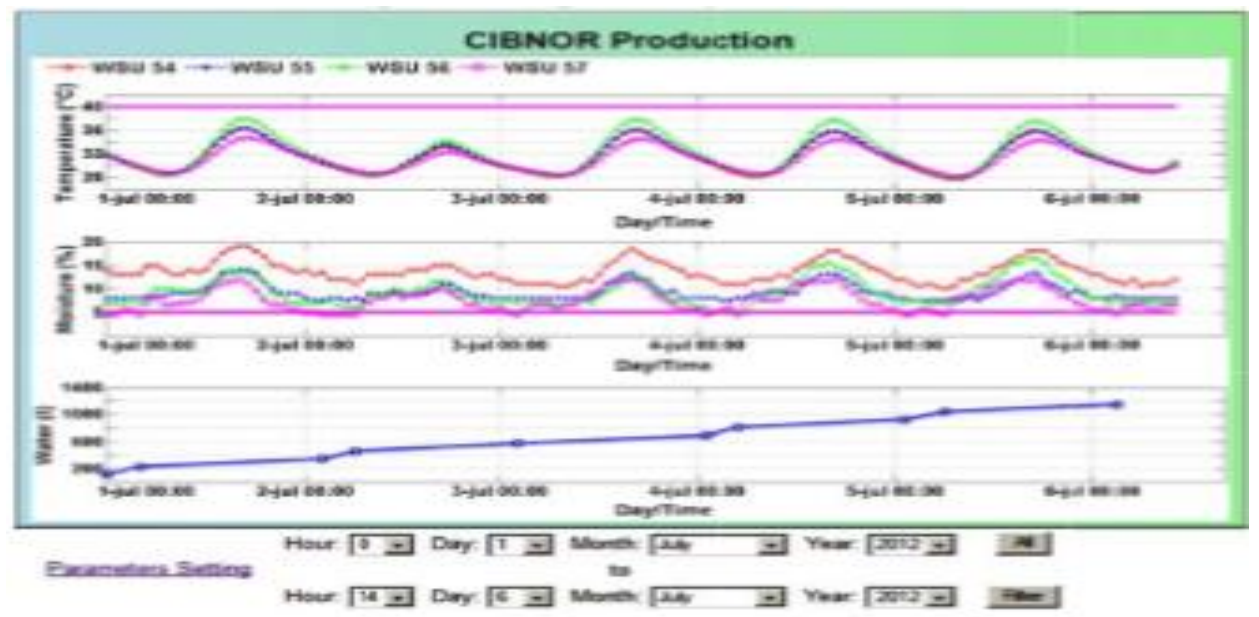

- $\quad$ Collection of the data of the Wireless Sensor Unit, in the webpage application of the automating farming system: soil moisture, soil temperatures, and water supplied (vertical bars indicate automated and scheduled irrigation).In the sample picture below. 


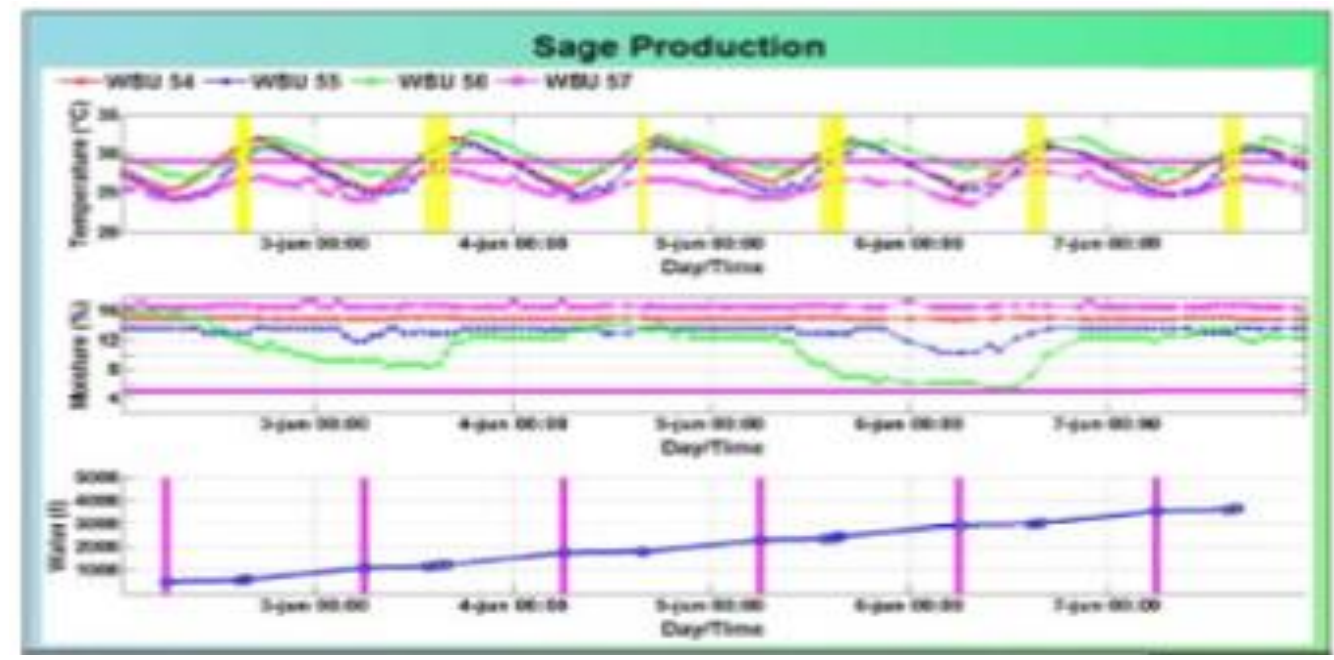

\section{References}

[1] Devices for Automatic Irrigation Based on GSM Network and Radio Communication published in Control, Automation, Robotics and Vision 9th International Conference on 2016 by IEEE.

[2] Automated Irrigation System Using a Wireless Sensor Network and GPRS Module published in IEEE transaction on Instrumentation and Measurement. 0018-9456 C 2013 IEEE.

[3] Smart farming using Arduino and data mining INSPEC Accession Number: 16426771Publisher: IEEE Conference Location: New Delhi, India Date of Conference: 16-18 March 2016.

[4] S. R. Nandurkar, V. R. Thool, R. C. Thool, "Design and Development of Precision Agriculture System Using Wireless Sensor Network", IEEE International Conference on Automation, Control, Energy and Systems (ACES), 2014.

[5] Dr.V.Vidya Devi, G.Meena Kumari,"Real- Time Automation and Monitoring System for Modernized Agriculture" ,International Journal of Review and Research in Applied Sciences and Engineering (IJRRASE) Vol3 No.1. PP 7-12, 2013.

[6] S.V.Manikanthan and K.srividhya "An Android based secure access control using ARM and cloud computing", Published in: Electronics and Communication Systems (ICECS), 2015 2nd International Conference on 26-27 Feb. 2015,Publisher: IEEE,DOI: 10.1109/ECS.2015.7124833.

[7] T.Padmapriya, Ms. N. Dhivya, Ms U. Udhayamathi, "Minimizing Communication Cost In Wireless Sensor Networks To Avoid Packet Retransmission", International Innovative Research Journal of Engineering and Technology, Vol. 2, Special Issue, pp. $38-42$. 